\title{
Differences in the mitochondrial and lipid droplet morphology in female office workers with trapezius myalgia, compared to healthy controls.
}

\section{A muscle biopsy study.}

Kayleigh De Meulemeester $(\mathrm{MSc})^{1}$, Barbara Cagnie $(\mathrm{PT}, \mathrm{PhD})^{1}$, Jo Van Dorpe $(\mathrm{MD}, \mathrm{PhD})^{2}$, Martin Lammens (MD, PhD) $)^{3,4}$, Mirko Petrovic (MD, PhD) ${ }^{5}$, Patrick Calders $(\mathrm{PhD})^{1}$

${ }^{1}$ Department of Rehabilitation Sciences and Physiotherapy, Ghent University

${ }^{2}$ Department of Pathology, Ghent University, Ghent, Belgium

${ }^{3}$ Department of Pathology, Antwerp University Hospital, Edegem, Antwerp, Belgium

${ }^{4}$ Laboratory of Neuropathology, Institute Born-Bunge, University of Antwerp, Antwerp, Belgium

${ }^{5}$ Department of Internal medicine (Geriatrics), Ghent University, Ghent, Belgium

Corresponding author:

Kayleigh De Meulemeester

Corneel Heymanslaan 10,

9000 Ghent (Belgium)

$+3293321219$

Kayleigh.demeulemeester@ugent.be

No conflicts of interest were present in writing this article.

Kayleigh De Meulemeester is funded by BOF- UGent 01 N04215. 
Abstract

Objective

Trapezius myalgia, or more specific, myofascial dysfunction of the upper trapezius mainly affects women performing jobs requiring prolonged low level activation of the muscle. This continuous low muscle load can be accompanied by a shift to a more anaerobic energy metabolism, causing pain. To investigate whether morphological signs of an impaired aerobic metabolism are present in female office workers with trapezius myalgia.

Design

Muscle biopsy analysis, using electron and light microscopy, was performed to compare mitochondrial and fat droplet morphology, and irregular muscle fibers, between female office workers with $(n=17)$ and without $(n=15)$ work-related trapezius myalgia.

Results

The patient group showed a significantly higher mean area $(\mathrm{P}=0.023)$ and proportion $(\mathrm{P}=0.029)$ for the subsarcolemmal and intermyofibrillar mitochondria respectively, compared to the control group. A significantly lower mean area of subsarcolemmal lipid droplets was found in the patient group $(\mathrm{P}=0.015)$, which also displayed a significantly higher proportion of lipid droplets touching the mitochondria $(\mathrm{P}=0.035)$. A significantly higher amount of muscle fibers with COX deficient areas were found in the patient group $(\mathrm{P}=0.030)$.

\section{Conclusion}

The results of the present study may be indicatve for an impaired oxidative metabolism in work-related trapezius myalgia. However, additional research is necessary to confirm this hypothesis.

Key words: mitochondria, lipid droplets, irregular fibers, neck pain, myofascial pain 


\section{Introduction}

Work-related neck pain is a prevalent musculoskeletal disorder, which mainly affects women and is associated with a high socio-economic burden ${ }^{(1-3)}$. In a study of Juul-Kristensen et al. (2006) on self-reported neck complaints in a population of screen workers, work-related trapezius myalgia (TM) was the most common clinical diagnosis ${ }^{(1)}$.

Trapezius myalgia, or more specific, myofascial dysfunction of the upper trapezius muscle (UT) is often present in jobs requiring prolonged static postures and repetitive upper limb movements, such as office work ${ }^{(2,4)}$. Also psychological stress plays an important role in the development and maintenance of myofascial dysfunction ${ }^{(5-7)}$.

The pathophysiology of myofascial pain is still not fully understood. It is hypothesized that continuous activation of the low threshold motor units (type I fibers), during prolonged low level muscle activity, leads to abnormal motor endplate activity, an excessive release of acetylcholine and a subsequent continuous local muscle contraction ${ }^{(8-10)}$. This persistent contraction can restrict the local muscle blood flow, causing tissue hypoxia. The imbalance between the limited local blood flow and thus reduced oxygen supply, and the increased energy need due to the continuous muscle activity, may lead to an energy crisis. This causes muscle distress and a release of sensitizing substances, which activate the nociceptors ${ }^{(10)}$. Besides this, the local tissue hypoxia may lead to a decreased $\mathrm{pH}$, activating specific pain receptors. It can be hypothesized that due to the local hypoxia, the aerobic energy metabolism is impaired in this patient population, causing a shift to a more anaerobic energy metabolism (9). Since mitochondria play a key role in the aerobic energy metabolism, it can be hypothesized that disturbances in the morphology or function of the mitochondria may contribute to this myofascial pain condition. Morphological signs of mitochondrial 
dysfunction have already been found in muscle tissue of fibromyalgia patients ${ }^{(11,12)}$. As mitochondria also play an important role in lipid oxidation, the morphology of lipid droplets can also provide relevant information about the aerobic energy metabolism ${ }^{(13)}$. Structural and functional abnormalities of mitochondria (e.g. a decline in mitochondrial density) are present in several diseases such as obesity and diabetes and are often associated with an increase in the amount and size of lipid droplets ${ }^{(14,15)}$. This storage of lipids can be a consequence of an impaired oxidative phosphorylation ${ }^{(14)}$.

In several studies about TM, irregular fibers have been identified in both patient and healthy control groups ${ }^{(16)}$. "Irregular fibers" is a collective term for muscle fibers which show signs of an aberrant mitochondrial morphology or function, when stained for a particular enzyme or part of the respiratory chain, and may serve as indirect evidence for a lack of mitochondria in these regions ${ }^{(14)}$. Several attempts for unravelling the underlying pathophysiology of TM have already been done by means of muscle biopsy analysis. However, to our best knowledge, no studies have been performed yet about the potential role of mitochondria and lipid droplets in this myofascial pain condition.

Therefore, the aim of the present study was to compare the mitochondrial and lipid droplet morphology, and the presence of irregular fibers between female office workers with and without TM.

Methods

Subjects

For this case-control study, female office workers between 20 and 50 years old were recruited from January to November 2016. E-mails and flyers were distributed among several workplaces with predominant computer-based tasks. Interested volunteers were asked to fill 
out an online questionnaire to check eligibility and to register relevant demographic information such as the perceived pain in the last week, as measured by the numeric rating scale (NRS), and their perceived disability caused by neck pain, as measured by the Neck Disability Index (NDI). The NRS was used to measure the mean, minimal and maximal neck/ shoulder pain during the past week. Subjects had to score their pain on a scale from zero (no pain) to ten (worst pain) ${ }^{(17)}$. The NDI (Dutch language version) is a valid questionnaire to measure self-reported neck-pain related disability ${ }^{(18)}$. In- and exclusion criteria were evaluated based the online questionnaire by the main researcher of this study (KDM) and are thoroughly described in De Meulemeester et al. (2019) ${ }^{(19)}$. All subjects signed an informed consent and the study was approved by the Local Ethics Committee of Ghent University Hospital. This study conforms to all STROBE guidelines and reports the required information accordingly (see Supplemental Checklist, Supplemental Digital Content 1, http://links.lww.com/PHM/A803).

\section{Muscle biopsies}

\section{Muscle biopsy sampling}

The biopsy location was marked at the palpated MTrP region at the midpoint between the spinous process of $\mathrm{C} 7$ and the lateral edge of the acromion. Details about the biopsy sampling are described in De Meulemeester et al.(2019) ${ }^{(19)}$.Each biopsy sample was cut into two pieces, one piece was stored in a solution of $4 \%$ paraformaldehyde and $5 \%$ glutaraldehyde in $0,1 \mathrm{M}$ cacodylate buffer for electron microscopy and another piece was mounted with Tissue-Tek (OCT compound), frozen in isopentane, precooled with liquid nitrogen and stored in a freezer at $-80{ }^{\circ} \mathrm{C}$ until they were stained to identify irregular muscle fibers. All biopsy samples were given a unique identification number and were blinded by an independent researcher. 
Biopsy samples were cut into smaller pieces (1 to $2 \mathrm{~mm}$ ) and stained with the fixative osmium tetroxide. Afterwards, the biopsy samples were dehydrated with ethanol and propylene oxide. Thereafter, the samples were placed in beem embedding capsules, in which Epon, an embedding medium, was added. After hardening the tissue overnight in an oven at $60^{\circ} \mathrm{C}$, the tissue was cut into longitudinal semi-thin sections of $4 \mu \mathrm{m}$, using a glass microtome system (Ultramicrotomy System, Pyramitome, LKB (Stockholm-Bromma, Sweden)). After a tissue orienting staining with toluidine blue, the semi-thin sections were cut with a diamond microtome (Reichert Supernova, Leica) at $90 \mathrm{~nm}$ and afterwards at $70 \mathrm{~nm}$. Then a staining with uranylacetate (to identify RNA, ribosomes, mitochondria and membranes) and lead nitrate (to mark filaments and the lipid droplets) was performed. Last, the muscle sections were covered with pulverized carbon powder. This EM procedure was performed by a skilled lab technician at the EM laboratory at the Pathology Department of Ghent University Hospital.

Analysis of electron microscopy images

Samples were viewed at 3000x magnification (for the analysis of lipid droplets) and at 12000x magnification (for the analysis of mitochondria) using a JEOL 1200EX transmission electron microscope. For each subject, 10 micrographs were acquired from 2 randomly sampled longitudinal sections of muscle fibers at 3000x magnification and 15 micrographs were selected of 3 randomly longitudinal sections at 12000x magnification. One micrograph was taken near the cell surface to visualize the subsarcolemmal region, the other micrographs were taken of parallel bundles of myofibrils, representing the intermyofibrillar region. The 
reference for subsarcolemmal space quantification was the cytoplasmic space between the sarcolemma and the first layer of myofibrils.

Specific criteria were set in advance for the identification of mitochondria and lipid droplets. Mitochondrial fragments and lipid droplets were circled and converted to actual size using a scale bar. For each set of 25 images, the mean mitochondrial and lipid droplet area $\left(\mu \mathrm{m}^{2}\right)$, the proportion of lipid droplets touching mitochondria (\%), the proportion of mitochondrial and lipid droplet area (\%), and the number of mitochondria and lipid droplets per square micrometer of muscle tissue $\left(\# / \mu \mathrm{m}^{2}\right)$ were calculated in the subsarcolemmal and intermyofibrillar compartments by digital imaging software (ImageJ 1.50i). Calculations were performed as follows: mean mitochondrial/lipid droplet size $\left(\mu \mathrm{m}^{2}\right)=$ sum of all mitochondrial or lipid droplet sizes/\# mitochondria or lipid droplets, proportion of lipid droplets touching mitochondria $(\%)=(\#$ lipid droplets touching mitochondria/ total \# lipid droplets $) \times 100 \%$, proportion of mitochondrial or lipid droplet area $(\%)=($ sum of all mitochondrial or lipid droplet sizes/ total tissue area) x $100 \%$, \# of mitochondria or lipid droplets per $\mu \mathrm{m}^{2}$ of muscle tissue $\left(\# / \mu \mathrm{m}^{2}\right)=\#$ mitochondria or lipid droplets/ total tissue area $\left(\mu \mathrm{m}^{2}\right)$. Important to note is that only mitochondria and lipid droplets with an area that was visualized completely on the image, were taken into account. The total tissue area consists of the area of the image that is covered with muscle tissue.

\section{Histological and histochemical staining of muscle tissue}

Transverse serial muscle cryosections $(4 \mu \mathrm{m})$ were cut by means of a freezing microtome (Microm $\mathrm{GmbH}$, type HM $550 \mathrm{OMVP}$, Germany) at a temperature of $-15^{\circ} \mathrm{C}$ and mounted on glass slides.

Afterwards the muscle cryosections were histologically stained with Gomori Trichrome to visualize subsarcolemmal or intermyofibrillar accumulation of mitochondria, called ragged 
red fibers. Besides, irregular muscle fibers were identified using histochemical reactions for Nicotinamide Adenine Dinucleotide (NADH), and oxidative enzymes Cytochrome C Oxidase (COX) and Succinate Dehydrogenase (SDH). This was performed by skilled lab technicians in the clinical laboratory at the Pathology Department of Ghent University Hospital.

Normally, a regulary ordered intermyofibrillar network is seen with these oxidative enzyme stains ${ }^{(14)}$. A common change or abnormality that can be visualized with these stains, is a disruption of the intermyofibrillar network with a patchy staining pattern or larger areas devoid of staining. This may reflect a loss of myofibrils and a disturbed mitochondrial distribution.

\section{Analysis of histochemical staining images}

Light microscopic images of the histochemical stainings were captured by means of a 3D Histech Panoramic 250 Flash III (CaseViewer 2.0 RTM and CaseCenter 2.7 of 3D Histech) in 20x Brightfield modus. The images of the transverse sections were digitalized by means of 3D Histech Panoramic 250 Flash III in collaboration with Bimetra Biobank, Ghent, Belgium (ID: $\mathrm{BE}$ 71067049). For each subject, at least three areas were randomly selected by an independent researcher and used for the determination of ragged red fibers and muscle fibers with an aberrant staining for $\mathrm{NADH}, \mathrm{COX}$, and $\mathrm{SDH}$. Image analysis was performed using ImageJ $1.50 \mathrm{i}$, muscle fibers with an abnormal staining pattern were manually counted with the Cell Counter Plugin.

\section{Statistical analysis}

Data were analysed using SPSS Version 20.0 (IBM Corporation, Armonk, NY) software. Mean and standard deviation (in case of normal distribution), median and interquartile range (in case of non-normal distribution) or proportions were estimated for demographics. Group 
differences for demographics were assessed using unpaired T-tests in case of normal distribution, Mann-Whitney $U$ test in case of non-normal distribution and Chi squared tests in case of categorical data. Descriptive statistics (mean \pm standard deviation and $95 \%$ confidence interval or median (IQR) and min-max) were estimated for all outcome measures. A multiple linear regression model was applied for each outcome measure with "group" (2 levels: myalgia group and control group) as a categorical predictor. Relevant covariates (age, hours of computer work per week, and performing upper limb sports) were added to the model for each outcome measure. The model was checked for multicollinearity. The residuals of each model were checked for normality and homoscedasticity. Statistical significance was accepted at $\alpha<0.05$.

Results

The online questionnaire was completed by 111 women. After screening of the questionnaire and performing the clinical examination, 32 female office workers, of which 17 patients and 15 healthy controls, were found eligible to be included in the study. Descriptive statistics of demographic features and outcome measures are shown in Table 1 and 2.

\section{Mitochondria and lipid droplets}

For the electron microscopic analysis, the muscle sample of one patient was excluded due to problems during the tissue preparation. Fifty images of 20 different subjects were excluded due to low image quality. Results of the linear regression analysis are presented in Table 3 . In all subjects (both patients and controls), ultrastructural changes were seen in the muscle tissue such as focal loss of myofibrils, splitting and/or narrowing myofibrils, areas of disorganized myofibrils, irregular Z-lines and Z-line loss. 


\section{Mitochondria}

A significantly higher mean area $\left(\mu \mathrm{m}^{2}\right)$ was found for the subsarcolemmal mitochondria in the patient group, compared to the healthy control group $(\mathrm{P}=0.023)$. The intermyofibrillar mitochondria cover a significantly higher area $(\%)$ in the patient group, compared to the healthy control group $(\mathrm{P}=0.029)$. No significant differences were found for the other outcome parameters $(\mathrm{P}>0.05)$. A borderline missed significantly higher intermyofibrillar mean mitochondrial area was found for the patient group $(\mathrm{P}=0.051)$. As an example, an image of subsarcolemmal and intermyofibrillar mitochondria in a patient is shown at a $12000 \mathrm{x}$ magnification in Figure 1.

\section{Lipid droplets}

A significantly smaller mean area $\left(\mu \mathrm{m}^{2}\right)$ was found for the subsarcolemmal lipid droplets in the patient group, compared to the control group $(\mathrm{P}=0.015)$. The percentage of intermyofibrillar lipid droplets, touching the mitochondria, was significantly larger in the patient group, compared to the control group $(\mathrm{P}=0.035)$. No significant differences were found for the other outcome parameters $(\mathrm{P}>0.05)$. As an example, an image of subsarcolemmal and intermyofibrillar lipid droplets in a patient is shown at a $3000 \mathrm{x}$ magnification in Figure 2.

\section{Irregular fibers}

For the morphometric analysis of irregular fibers, several samples were excluded due to freezing artefarcts, limited amount of muscle tissue or a failed staining. The Gomori Trichrome staining was performed on 10 patients and 10 controls. The amount of included subjects for COX, NADH and SDH stains are shown in Table 2. 
Despite the occurrence of several muscle fibers with a disorganized mitochondrial pattern, the Gomori Trichrome staining revealed no ragged red fibers in none of the groups. A significantly higher proportion of muscle fibers with an irregular COX staining was found in the patient group, compared to the control group $(\mathrm{P}=0.030)$. Despite the finding that muscle fibers with areas of irregular COX staining also showed areas with irregular NADH and SDH staining, no significant differences between both groups were found for NADH and SDH $(\mathrm{P}>0.05)$. An image of a $\mathrm{COX}, \mathrm{NADH}$ and $\mathrm{SDH}$ staining in a patient and a healthy control is shown in Figure 3, 4 and 5 respectively.

When interpreting the adjusted $\mathrm{R}^{2}$ and P-values of the model (Table 3 ), we can conclude that the independent variable "group" only has a small contribution to the variance of the outcome measure. So, there must be several other factors contributing to the outcome measures apart from the group to which a subject belongs.

\section{Discussion}

To our best knowledge this is the first study in which mitochondrial and lipid droplet morphology is studied in patients with TM. The present study revealed a significantly higher mean area and proportion in the patient group for SS and IMF mitochondria respectively. Mitochondrial area and proportion are usually positively correlated with mitochondrial function and aerobic capacity. An increased mitochondrial area is for example seen in response to endurance training ${ }^{(20-22)}$. In a previous study on the same study sample was shown that significantly more type IIA and significantly more type IIAX (although not clinically meaningful), and significantly less type IIX fibers were present in the TM group ${ }^{(19)}$. It can be hypothesized that a higher load on these mixed aerobic/anaerobic type IIA muscle fibers ${ }^{(23)}$ in the patient group, could have triggered mitochondrial proliferation to increase 
oxidative capacity, explaining the observed difference in mitochondrial density. Since we could not distinguish fiber types on EM, we can however not confirm this hypothesis. It can also be hypothesized that the larger mitochondrial mean area and proportion is a compensatory mechanism for an impaired mitochondrial function. This potential compensatory mechanism was found in a study on mouse models for mitochondrial myopathy, where an increased mitochondrial volume density together with decreased respiratory chain enzyme activities was found in skeletal muscle tissue ${ }^{(24)}$. Besides, an increased mitochondrial number and size was also found in patients with mitochondrial disorders ${ }^{(25)}$.

The significantly higher amount of muscle fibers with COX deficient areas found in the patient group, compared to the healthy control group, contributes to this hypothesis. However, it must be noted that this was the only respiratory complex that showed significant differences so this hypothesis should be approached with caution. Cytochrome $\mathrm{C}$ oxidase is an enzyme in the mitochondrial respiratory chain which corresponds to complex IV and is essential for the reduction of molecular oxygen to water ${ }^{(26)}$. These COX deficient areas can correspond to areas with a loss of mitochondria, which is indicative for a structural myopathy.

In contrast to the results of this study, no significant differences in muscle fibers with COX deficient areas were found between patients with TM and healthy controls in the study of Larsson et al.(2000) ${ }^{(27)}$. In recent studies about patients with specific muscle diseases, muscle fibers with COX deficient areas, together with decreased activities of respiratory complexes were found ${ }^{(28,29)}$. In future studies it may be useful to investigate the mitochondrial respiratory enzyme activities by means of spectrophotometric enzyme analysis ${ }^{(30)}$. This allows to distuingish between true respiratory complex defects or a decreased mitochondrial content ${ }^{(31)}$. However, this technique requires more muscle tissue than can be obtained by microbiopsy. 
Ragged red fibers, which are a marker for a disturbed mitochondrial metabolism, were found in none of the groups. In the study of Kadi et al. (1998) and Lindman et al. (1991) ragged red fibers were rarely detected in women with work-related $\mathrm{TM}^{(32,33)}$. In contrast, a significantly higher amount of ragged red fibers was found in cleaners with and without TM, when compared to healthy teachers ${ }^{(27)}$. No significant differences were found between both groups for SDH (complex II of the respiratory chain) and NADH. No specific results were reported in previous studies regarding SDH since mostly combined COX/SDH stains were used ${ }^{(27,32)}$. Regarding NADH, our results are in line with the findings of Larsson et al. (2004) where no significant differences were found between female cleaners with and without $\mathrm{TM}^{(34)}$. Larsson et al. (2004) and Lindman et al. (1991) however, did find significant differences in NADH deficient fibers between a patient and control group with a different occupation ${ }^{(33,34)}$. It can be hypothesized that changes in $\mathrm{NADH}$ are rather work-related instead of pain-related. Irregular muscle fibers usually have a segmental appearance and their occurrence is also dependent on biopsy location and size, which can also explain the variable results in different studies ${ }^{(14,27)}$.

In this study also a significantly lower mean area of SS lipid droplets was found in the patient group, compared to the healthy control group. From a metabolic point of view, it is more beneficial to have more and smaller lipid droplets instead of fewer and larger droplets because of the greater surface area for proteins, responsible for lipid droplet turnover ${ }^{(22)}$. It can be hypothesized that this is also a mechanism to compensate for a decreased mitochondrial function. Another possible explanation is that in the patient group a significantly lower amount of type I fibers was found ${ }^{(19)}$. Since lipid droplets are more abundantly present in type I fibers ${ }^{(20,35)}$, it is possible that this difference in fiber type proportion is also reflected in lipid droplet density. Again, we were not able to distinguish between fiber types so this hypothesis cannot be confirmed based on this study. 
The patient group of this study displayed a significantly higher proportion of lipid droplets touching the mitochondria. First, it can be hypothesized that due to the significantly larger mitochondria in the patient group, there is also a higher probability of the larger mitochondria to make contact with more lipid droplets ${ }^{(22)}$. On the other hand, it can also reflect a structuralfunctional relationship to optimize the oxidative metabolism and thus aerobic capacity. For example, endurance leads to a higher amount of lipid droplets in direct contact of mitochondria in response to endurance exercise ${ }^{(22)}$. Also, in obese or diabetic people, it is found that an inability to oxidize lipid droplets, can lead to an accumulation of lipid byproducts which is reduced in case of a close proximity between lipid droplets and mitochondria ${ }^{(22)}$. It can be hypothesized that in the patient group, the lipid droplets, which are dynamic organelles, are being triggered to move towards the mitochondria in order to optimize lipid substrate utilization and thus energy production.

It can be hypothesized that the differences between both groups can be explained by a higher stress on the trapezius muscles in the patient group. Several studies have already shown that the EMG activity of the UT is significantly higher in a myalgia group, compared to a healthy control group ${ }^{(36-38)}$. Besides this, several studies have already demonstrated that the capillarisation is significantly lower in the patient groups with TM, compared to healthy controls ${ }^{(33,34)}$. It is possible that office workers who develop TM, have a lower capillarisation by genetic predisposition, making them more vulnerable for the development of this condition. So another possible hypothesis is that an increased mitochondrial mean area and proportion, and a mobilization of the lipid droplets towards the mitochondria, are a consequence of the higher demands where the mitochondria are subjected to because of the muscle overload and restricted oxygen supply during office work. 
Lastly, it has already been shown that mental stress plays an important role in the development and maintenance of neck and shoulder pain ${ }^{(39-41)}$. Since we did not monitor the mental stress level in both groups, it may be possible that the patient group experiences more mental stress than the control group, leading to significant morphological differences.

\section{Strengths and limitations}

A strength of this study is the use of electron microscopy as an investigation technique for the quantification of mitochondrial and lipid droplet morphology. Electron microscopy enables a

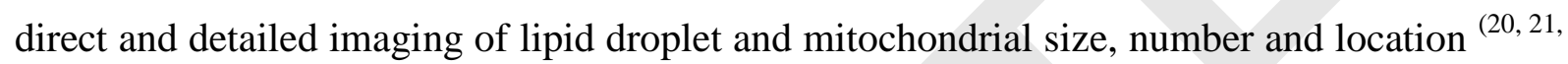
$42,43)$. Another strength is that muscle biopsy samples were taken from the dominant side in both the patient and control group, which excludes differences in muscle morphology due to hand preferences.

A first limitation of the present study is that no distinction was made in the location of mitochondria and lipid droplets regarding fiber types. Mitochondria and lipid droplets are usually more abundant in oxidative type I fibers, compared to type II fibers ${ }^{(20,35)}$. Since mitochondrial and lipid droplet content is dependent on the fiber type distribution of the muscle tissue ${ }^{(14,44)}$, it might be relevant to compare the distribution of mitochondria and lipid droplets between the patient and control group. It is also important to mention that the analysis of two-dimensional electron microscopic images does not reflect the fact that every visible mitochondrion is actually a fragment of the three-dimensional mitochondrion ${ }^{(45-47)}$. A second limitation is that the enzymatic activity of the respiratory chain complexes was not investigated. However, the analysis of enzymatic activity requires a much higher amount of muscle tissue than obtained by means of microbiopsy, thus another, more invasive biopsy technique is then required. A third limitation is that no combined COX /SDH staining was 
performed. A combined COX/SDH staining allows a clearer identification of fibers with a mosaic pattern of COX deficient and COX normal fibers, which is indicative for a mitochondrial DNA defect ${ }^{(14)}$. A last limitation is the loss of muscle tissue due to freezing artefacts, which had a negative impact on our included sample size for the evaluation of irregular muscle fibers and may have negatively influenced the reliability and sensitivity of the present results.

Considerations for further research

In future studies more attention could be paid on the clinical presentation of the patients with TM. A more thorough examination of clinical features such as range of motion, strength and postural awareness could for example be correlated to the morphological outcome measures. It would also be of added value to monitor lifestyle factors such as sleep, nutrition, smoking, physical activity and stress and to investigate the influence of these factors on the development and maintenance of TM. It would be interesting to conduct longitudinal followup studies in which office workers without neck pain are followed over time and clinical and morphological features are monitored at several time points. In addition, the effectiveness of several treatment techniques such as dry needling ${ }^{(48)}$, manual compression techniques ${ }^{(48)}$ and exercise therapy ${ }^{(49-51)}$ could be studied by evaluating the effect on morphological features of the UT.

\section{Conclusion}

In this muscle biopsy study on female office workers with and without work-related TM, several morphological differences in mitochondira, lipid droplets and COX deficient fibers were found. Whether these differences indicate an improved aerobic capacity or reflect a 
compensatory mechanism for a decreased mitochondrial function, which may be associated with TM, remains elusive and requires further research.

\section{Acknowledgements}

We thank Lynn Supply, Ran Rumes and the staff of Bimetra Biobank, Ghent (Belgium) for their excellent technical assistance. 


\section{References}

1. Juul-Kristensen B, Kadefors R, Hansen K, Bystrom P, Sandsjo L, Sjogaard G. Clinical signs and physical function in neck and upper extremities among elderly female computer users: the NEW study. Eur J Appl Physiol. 2006;96(2):136-45.

2. Larsson B, Sogaard K, Rosendal L. Work related neck-shoulder pain: a review on magnitude, risk factors, biochemical characteristics, clinical picture and preventive interventions. Best Pract Res Clin Rheumatol. 2007;21(3):447-63.

3. Buckle PW, Devereux JJ. The nature of work-related neck and upper limb musculoskeletal disorders. Appl Ergon. 2002;33(3):207-17.

4. Ranney D, Wells R, Moore A. Upper limb musculoskeletal disorders in highly repetitive industries: precise anatomical physical findings. Ergonomics. 1995;38(7):1408-23.

5. Eijckelhof BH, Bruno Garza JL, Huysmans MA, Blatter BM, Johnson PW, van Dieen $\mathrm{JH}$, et al. The effect of overcommitment and reward on muscle activity, posture, and forces in the arm-wrist-hand region--a field study among computer workers. Scand J Work Environ Health. 2013;39(4):379-89.

6. Shahidi B, Haight A, Maluf K. Differential effects of mental concentration and acute psychosocial stress on cervical muscle activity and posture. J Electromyogr Kinesiol. 2013;23(5):1082-9.

7. Taib MF, Bahn S, Yun MH. The effect of psychosocial stress on muscle activity during computer work: Comparative study between desktop computer and mobile computing products. Work. 2016;54(3):543-55.

8. Simons DG. New views of myofascial trigger points: etiology and diagnosis. Arch Phys Med Rehabil. 2008;89(1):157-9.

9. Gerwin RD, Dommerholt J, Shah JP. An expansion of Simons' integrated hypothesis of trigger point formation. Curr Pain Headache Rep. 2004;8(6):468-75. 
10. Simons DG. Review of enigmatic MTrPs as a common cause of enigmatic musculoskeletal pain and dysfunction. J Electromyogr Kinesiol. 2004;14(1):95-107.

11. Park JH, Niermann KJ, Olsen N. Evidence for metabolic abnormalities in the muscles of patients with fibromyalgia. Curr Rheumatol Rep. 2000;2(2):131-40.

12. Sprott H, Salemi S, Gay RE, Bradley LA, Alarcon GS, Oh SJ, et al. Increased DNA fragmentation and ultrastructural changes in fibromyalgic muscle fibres. Ann Rheum Dis. 2004;63(3):245-51.

13. Hoppeler H. Exercise-induced ultrastructural changes in skeletal muscle. Int J Sports Med. 1986;7(4):187-204.

14. Dubowitz V, Sewry CA, OLdfors A. Muscle biopsy. A practical approach. 4 ed. China: Saunders, Elsevier; 2013.

15. Ritov VB, Menshikova EV, He J, Ferrell RE, Goodpaster BH, Kelley DE. Deficiency of subsarcolemmal mitochondria in obesity and type 2 diabetes. Diabetes. 2005;54(1):8-14.

16. De Meulemeester K, Calders P, De Pauw R, Grymonpon I, Govaerts A, Cagnie B. Morphological and physiological differences in the upper trapezius muscle in patients with work-related trapezius myalgia compared to healthy controls: A systematic review. Musculoskelet Sci Pract. 2017;29:43-51.

17. Jensen MP, Turner JA, Romano JM, Fisher LD. Comparative reliability and validity of chronic pain intensity measures. Pain. 1999;83(2):157-62.

18. Jorritsma W, de Vries GE, Dijkstra PU, Geertzen JH, Reneman MF. Neck Pain and Disability Scale and Neck Disability Index: validity of Dutch language versions. Eur Spine J. 2012;21(1):93-100.

19. De Meulemeester K, Calders P, Van Dorpe J, De Pauw R, Petrovic M, Cagnie B. Morphological Differences in the Upper Trapezius Muscle Between Female Office Workers 
With and Without Trapezius Myalgia: Facts or Fiction?: A Cross-Sectional Study. Am J Phys Med Rehabil. 2019;98(2):117-24.

20. Howald H, Hoppeler H, Claassen H, Mathieu O, Straub R. Influences of endurance training on the ultrastructural composition of the different muscle fiber types in humans. Pflugers Arch. 1985;403(4):369-76.

21. Hoppeler H, Luthi P, Claassen H, Weibel ER, Howald H. The ultrastructure of the normal human skeletal muscle. A morphometric analysis on untrained men, women and welltrained orienteers. Pflugers Arch. 1973;344(3):217-32.

22. Tarnopolsky MA, Rennie CD, Robertshaw HA, Fedak-Tarnopolsky SN, Devries MC, Hamadeh MJ. Influence of endurance exercise training and sex on intramyocellular lipid and mitochondrial ultrastructure, substrate use, and mitochondrial enzyme activity. Am J Physiol Regul Integr Comp Physiol. 2007;292(3):R1271-8.

23. Billeter R, Heizmann CW, Howald H, Jenny E. Analysis of myosin light and heavy chain types in single human skeletal muscle fibers. Eur J Biochem. 1981;116(2):389-95.

24. Wredenberg A, Wibom R, Wilhelmsson H, Graff C, Wiener HH, Burden SJ, et al. Increased mitochondrial mass in mitochondrial myopathy mice. Proc Natl Acad Sci U S A. 2002;99(23):15066-71.

25. Tassin S, Walter GF, Brucher JM, Rousseau JJ. Histochemical and ultrastructural analysis of the mitochondrial changes in a familial mitochondrial myopathy. Neuropathol Appl Neurobiol. 1980;6(5):337-47.

26. Chan SI, Li PM. Cytochrome c oxidase: understanding nature's design of a proton pump. Biochemistry. 1990;29(1):1-12.

27. Larsson B, Bjork J, Henriksson KG, Gerdle B, Lindman R. The prevalences of cytochrome c oxidase negative and superpositive fibres and ragged-red fibres in the trapezius 
muscle of female cleaners with and without myalgia and of female healthy controls. Pain. 2000;84(2-3):379-87.

28. Sunitha B, Gayathri N, Kumar M, Keshava Prasad TS, Nalini A, Padmanabhan B, et al. Muscle biopsies from human muscle diseases with myopathic pathology reveal common alterations in mitochondrial function. J Neurochem. 2016;138(1):174-91.

29. Liu F, Lou J, Zhao D, Li W, Zhao Y, Sun X, et al. Dysferlinopathy: mitochondrial abnormalities in human skeletal muscle. Int J Neurosci. 2015.

30. Haas RH, Parikh S, Falk MJ, Saneto RP, Wolf NI, Darin N, et al. The in-depth evaluation of suspected mitochondrial disease. Mol Genet Metab. 2008;94(1):16-37.

31. Reisch AS, Elpeleg O. Biochemical assays for mitochondrial activity: assays of TCA cycle enzymes and PDHc. Methods Cell Biol. 2007;80:199-222.

32. Kadi F, Waling K, Ahlgren C, Sundelin G, Holmner S, Butler-Browne GS, et al. Pathological mechanisms implicated in localized female trapezius myalgia. Pain. 1998;78(3):191-6.

33. Lindman R, Hagberg M, Angqvist KA, Soderlund K, Hultman E, Thornell LE. Changes in muscle morphology in chronic trapezius myalgia. Scand J Work Environ Health. $1991 ; 17(5): 347-55$.

34. Larsson B, Bjork J, Kadi F, Lindman R, Gerdle B. Blood supply and oxidative metabolism in muscle biopsies of female cleaners with and without myalgia. Clin J Pain. 2004;20(6):440-6.

35. Gouspillou G, Sgarioto N, Norris B, Barbat-Artigas S, Aubertin-Leheudre M, Morais JA, et al. The relationship between muscle fiber type-specific PGC-1alpha content and mitochondrial content varies between rodent models and humans. PLoS One. 2014;9(8):e103044. 
36. Leonard JH, Kok KS, Ayiesha R, Das S, Roslizawati N, Vikram M, et al. Prolonged writing task: comparison of electromyographic analysis of upper trapezius muscle in subjects with or without neck pain. Clin Ter. 2010;161(1):29-33.

37. Sjogaard G, Zebis MK, Kiilerich K, Saltin B, Pilegaard H. Exercise training and work task induced metabolic and stress-related mRNA and protein responses in myalgic muscles. Biomed Res Int. 2013;2013:984523.

38. Sjors A, Larsson B, Dahlman J, Falkmer T, Gerdle B. Physiological responses to lowforce work and psychosocial stress in women with chronic trapezius myalgia. BMC Musculoskelet Disord. 2009;10:63.

39. Malchaire J, Cock N, Vergracht S. Review of the factors associated with musculoskeletal problems in epidemiological studies. Int Arch Occup Environ Health. 2001;74(2):79-90.

40. Bongers PM, Kremer AM, ter Laak J. Are psychosocial factors, risk factors for symptoms and signs of the shoulder, elbow, or hand/wrist?: A review of the epidemiological literature. Am J Ind Med. 2002;41(5):315-42.

41. Waersted M. Human muscle activity related to non-biomechanical factors in the workplace. Eur J Appl Physiol. 2000;83(2-3):151-8.

42. Devries MC, Lowther SA, Glover AW, Hamadeh MJ, Tarnopolsky MA. IMCL area density, but not IMCL utilization, is higher in women during moderate-intensity endurance exercise, compared with men. Am J Physiol Regul Integr Comp Physiol. 2007;293(6):R233642.

43. Howald H, Boesch C, Kreis R, Matter S, Billeter R, Essen-Gustavsson B, et al. Content of intramyocellular lipids derived by electron microscopy, biochemical assays, and (1)H-MR spectroscopy. J Appl Physiol (1985). 2002;92(6):2264-72. 
44. Schrauwen-Hinderling VB, Hesselink MK, Schrauwen P, Kooi ME. Intramyocellular lipid content in human skeletal muscle. Obesity (Silver Spring). 2006;14(3):357-67.

45. Mannella CA, Buttle K, Rath BK, Marko M. Electron microscopic tomography of ratliver mitochondria and their interaction with the endoplasmic reticulum. Biofactors. 1998;8(34):225-8.

46. Perkins G, Renken C, Martone ME, Young SJ, Ellisman M, Frey T. Electron tomography of neuronal mitochondria: three-dimensional structure and organization of cristae and membrane contacts. J Struct Biol. 1997;119(3):260-72.

47. Perkins GA, Frey TG. Recent structural insight into mitochondria gained by microscopy. Micron. 2000;31(1):97-111.

48. Cagnie B, Castelein B, Pollie F, Steelant L, Verhoeyen H, Cools A. Evidence for the Use of Ischemic Compression and Dry Needling in the Management of Trigger Points of the Upper Trapezius in Patients with Neck Pain: A Systematic Review. Am J Phys Med Rehabil. 2015;94(7):573-83.

49. Kadi F, Ahlgren C, Waling K, Sundelin G, Thornell LE. The effects of different training programs on the trapezius muscle of women with work-related neck and shoulder myalgia. Acta Neuropathol. 2000;100(3):253-8.

50. Nielsen PK, Andersen LL, Olsen HB, Rosendal L, Sjogaard G, Sogaard K. Effect of physical training on pain sensitivity and trapezius muscle morphology. Muscle Nerve. 2010;41(6):836-44.

51. Sogaard K, Blangsted AK, Nielsen PK, Hansen L, Andersen LL, Vedsted P, et al. Changed activation, oxygenation, and pain response of chronically painful muscles to repetitive work after training interventions: a randomized controlled trial. Eur J Appl Physiol. 2012;112(1):173-81. 
Figure legends

Figure 1 Subsarcolemmal and intermyofibrillar mitochondria (12000 x magnification) in a healthy control

White asterisks indicate subsarcolemmal mitochondria, black asterisks indicate intermyoribrillar mitochondria

Figure 2 Subsarcolemmal and intermyofibrillar lipid droplets (3000 x magnification) in a patient

White asterisks indicate subsarcolemmal lipid droplets, black asterisks indicate intermyoribrillar lipid doplets

Figure 3 Enzymohistochemical staining for $\mathrm{COX}$ of muscle fibers in the upper trapezius muscle

A: muscle tissue of a healthy control, B: muscle tissue of a patient

Figure 4 Enzymohistochemical staining for NADH of muscle fibers in the upper trapezius muscle

A: muscle tissue of a healthy control, B: muscle tissue of a patient

Figure 5 Enzymohistochemical staining for SDH of muscle fibers in the upper trapezius muscle

A: muscle tissue of a healthy control, B: muscle tissue of a patient 
Figure 1

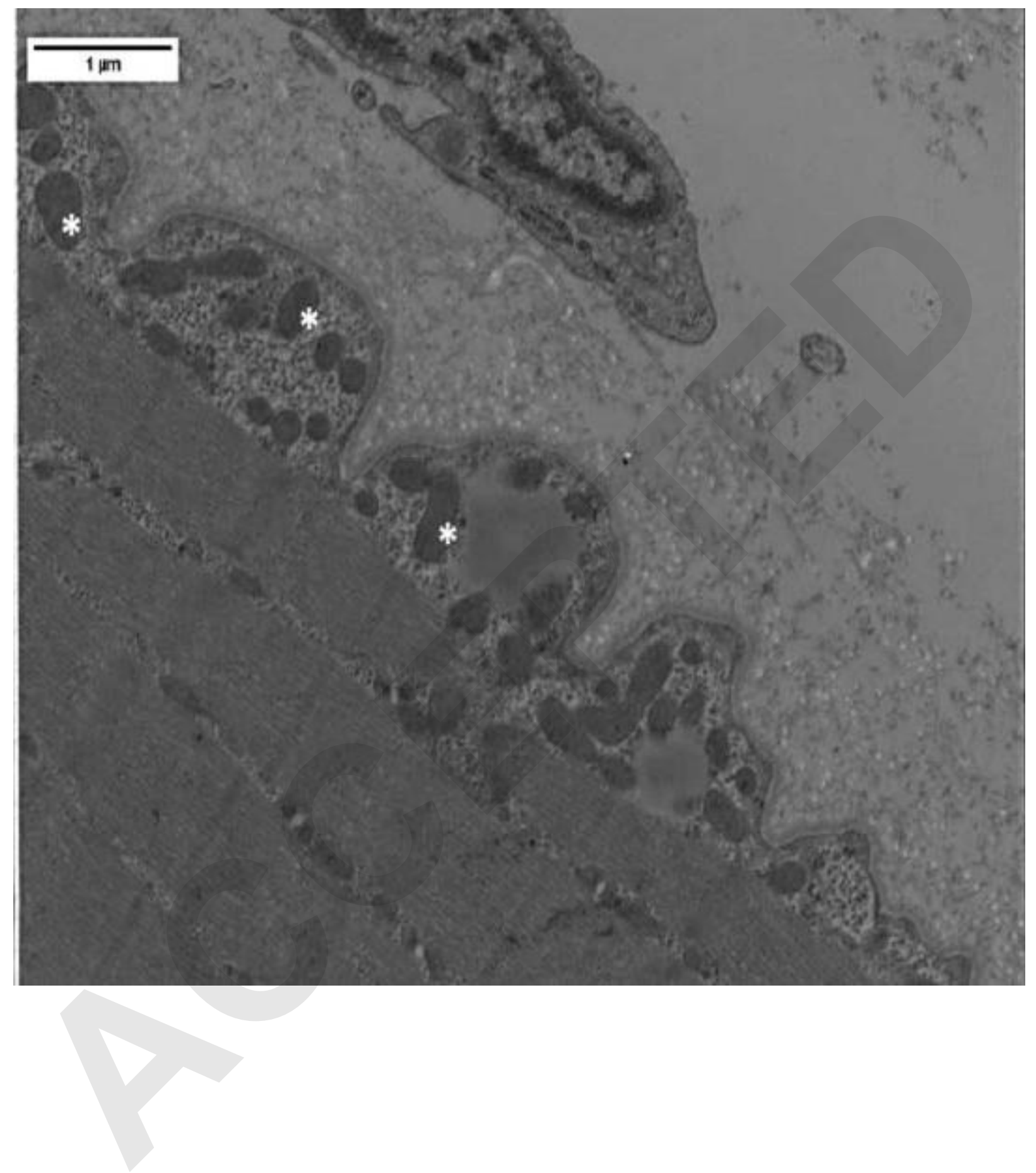


Figure 2

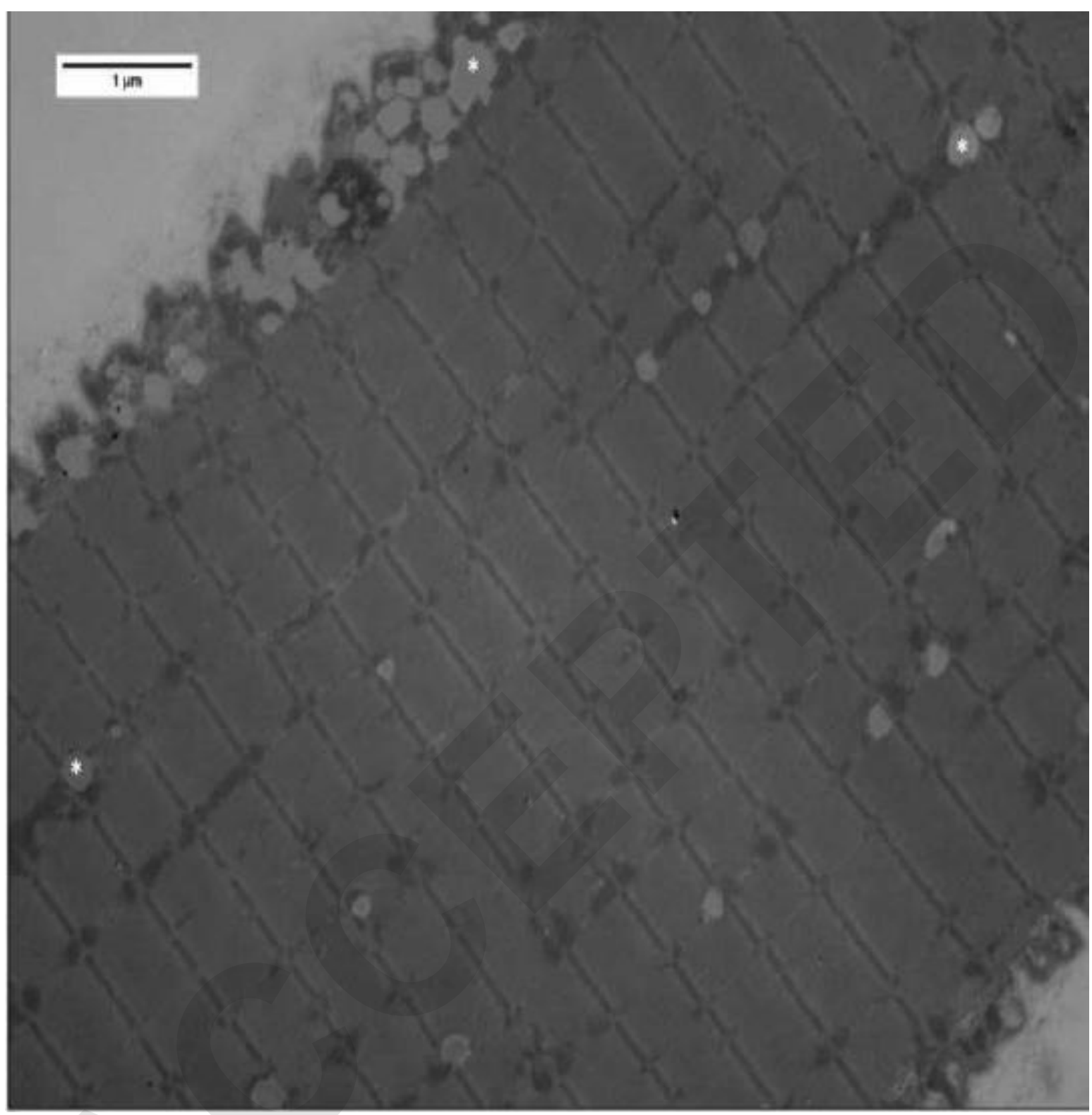


Figure 3

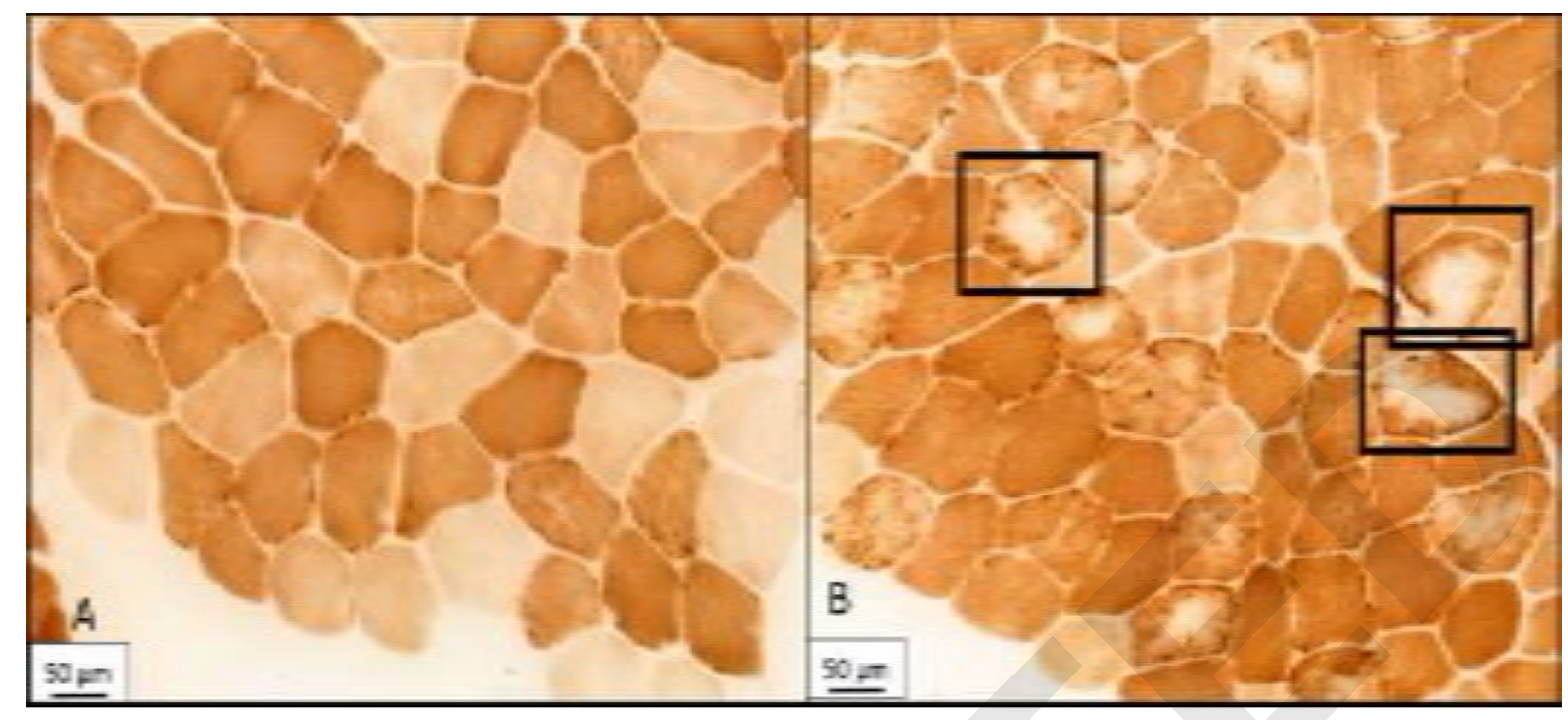




\section{Figure 4}

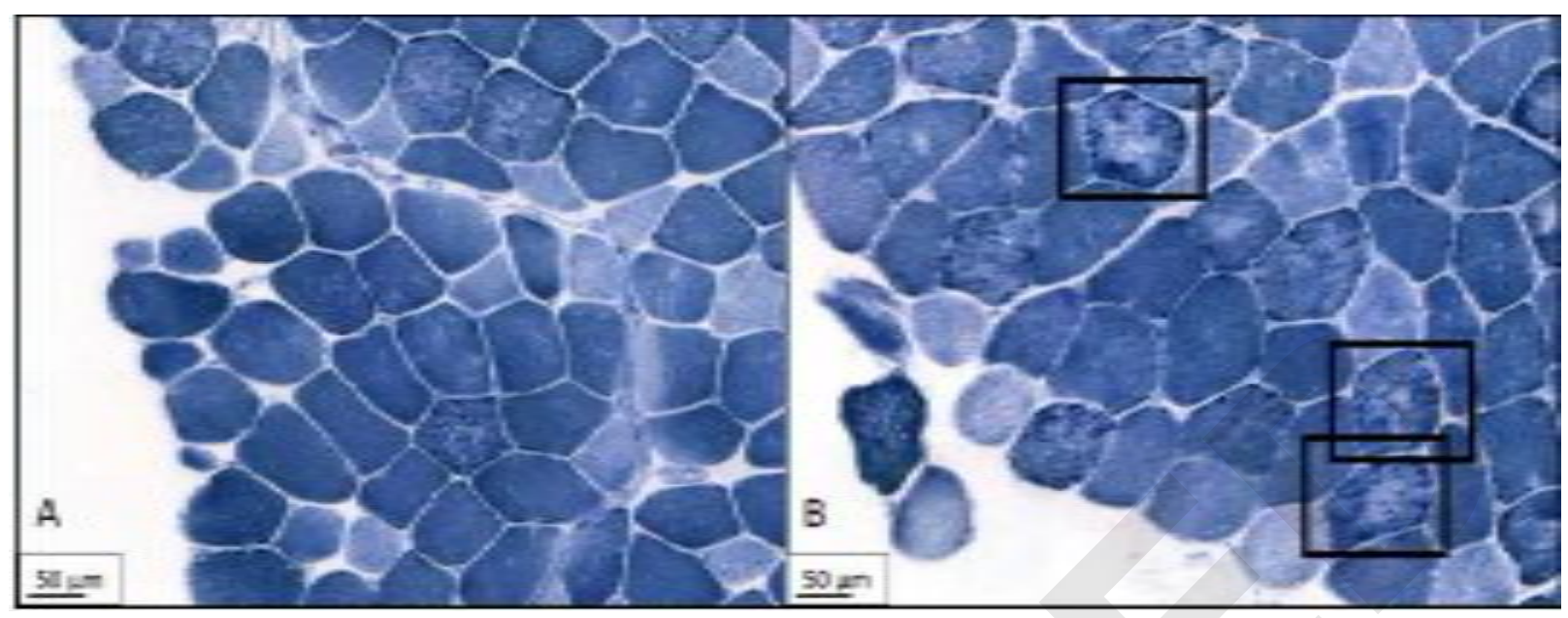




\section{Figure 5}

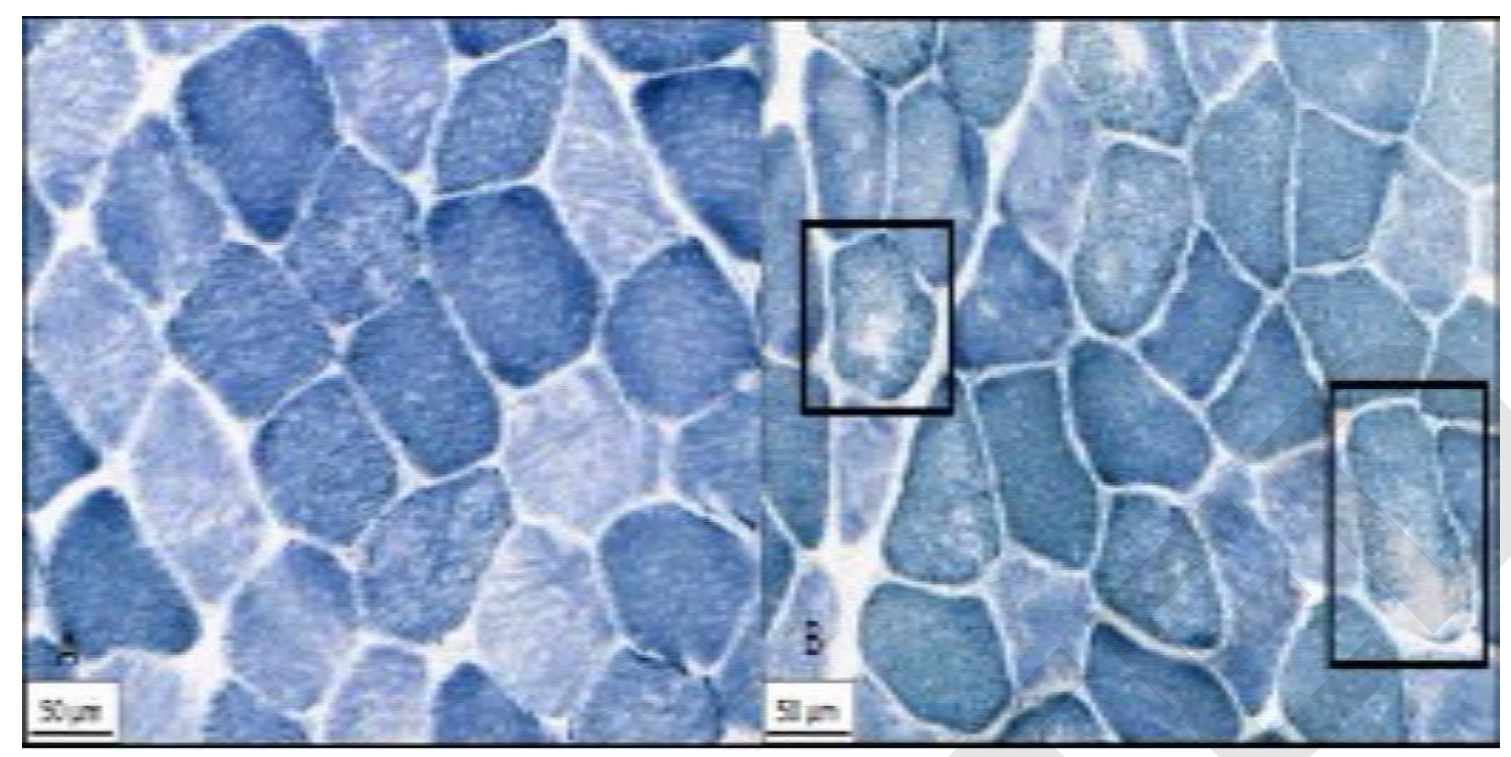


Table 1 Demographic data of the patient group and healthy control group

\begin{tabular}{|c|c|c|c|c|c|}
\hline & \multicolumn{2}{|c|}{ Patient group $(\mathrm{n}=16)$} & \multicolumn{2}{|c|}{ Control group $(n=15)$} & \multirow[t]{2}{*}{ P-value ${ }^{\S}$} \\
\hline & $\begin{array}{l}\text { Mean/med } \\
\text { ian or } \\
\text { frequencie } \\
\mathrm{s}\end{array}$ & SD or IQR & $\begin{array}{l}\text { Mean/med } \\
\text { ian or } \\
\text { frequencie } \\
\mathrm{s}\end{array}$ & SD or IQR & \\
\hline Age $^{*}$ & 29.87 & 5.98 & 27 & 9 & 0.052 \\
\hline $\operatorname{BMI}\left(\mathrm{kg} / \mathrm{m}^{2}\right)^{*}$ & 23.10 & 2.80 & 21.93 & 1.95 & 0.111 \\
\hline NDI $(0-50)^{*}$ & 9.33 & 5 & 2.33 & 2.06 & $\mathrm{P}<0.001$ \\
\hline NRS $(0-10)^{\dagger}$ & 5 & 4 & $\mathrm{NA}$ & NA & NA \\
\hline $\begin{array}{l}\text { Duration neck pain } \\
\text { (months) }^{\dagger}\end{array}$ & 12 & 25 & NA & NA & NA \\
\hline $\begin{array}{l}\text { Hours computer work } \\
\text { per week }(21-30 \mathrm{~h} / 31 \text { - } \\
40 \mathrm{~h} />40 \mathrm{~h})^{\ddagger}\end{array}$ & $3 / 9 / 4$ & $\sqrt{ }$ & $5 / 8 / 2$ & & 0.685 \\
\hline $\begin{array}{l}\text { Upper limb sports } \\
(\text { yes/no })^{\dagger}\end{array}$ & $5 / 11$ & & $3 / 12$ & & 0.474 \\
\hline
\end{tabular}

n: number of subjects, SD: standard deviation, IQR: interquartile range, yr: years, BMI: body mass index, NDI: Neck Disability Index, NRS: Numeric Rating Scale, h: hours, NA: not applicable

$*$ Values are mean \pm standard deviation, $\uparrow$ Values are median (IQR), $\ddagger$ Values are frequencies, $\S \mathrm{P}$-values for continuous data were calculated using unpaired T-tests in case of normal 
distribution (BMI and NDI) or Mann-Whitney U Test in case of non-normal distribution (age), P-values for categorical data were calculated using Chi squared tests (hours computer work per week and upper limb sports) 
Table 2 Descriptive statistics for mitochondrial morphology, lipid droplets and irregular fibers

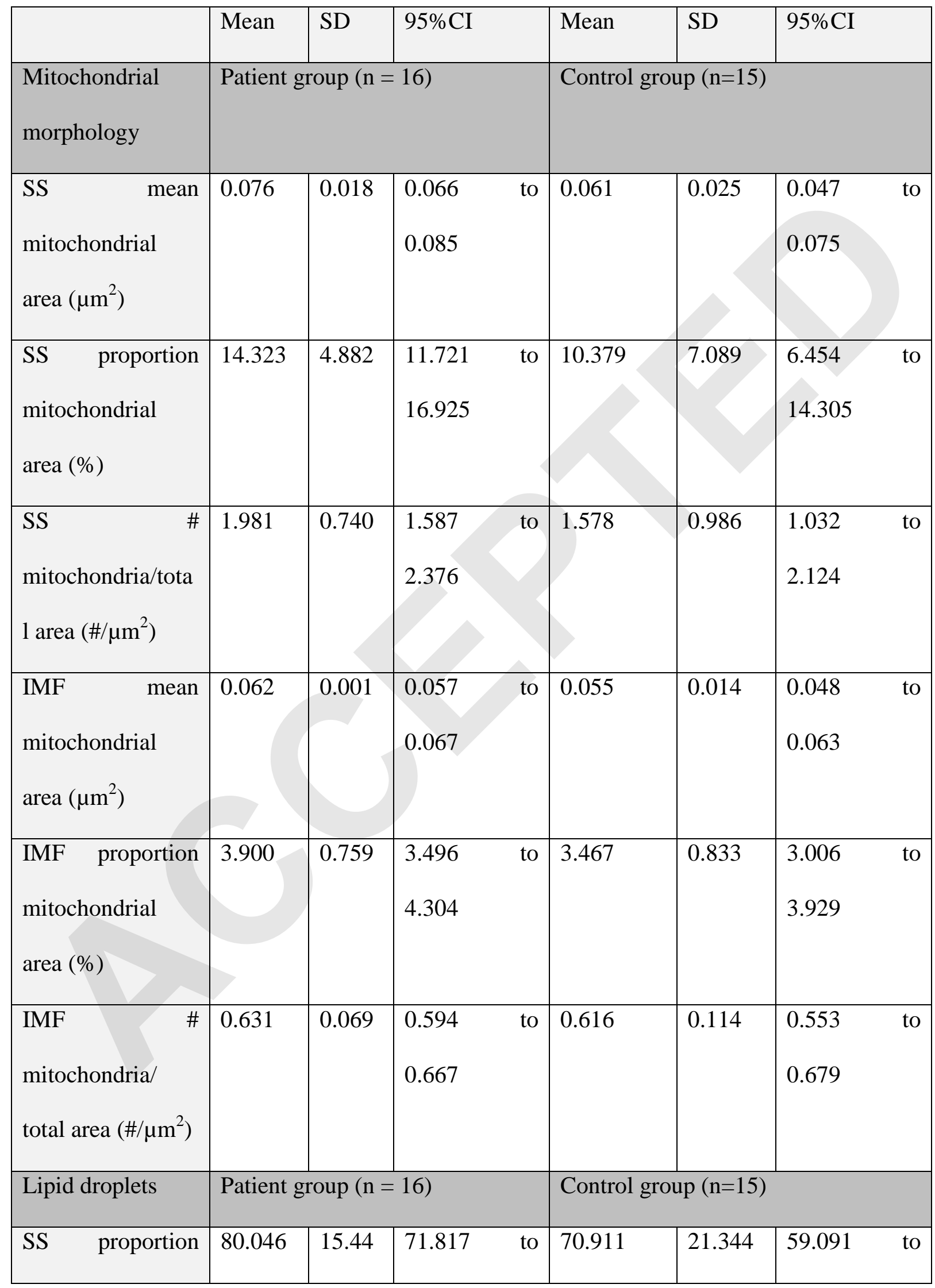




\begin{tabular}{|c|c|c|c|c|c|c|c|}
\hline $\begin{array}{l}\text { lipid droplets } \\
\text { touching } \\
\text { mitochondria (\%) }\end{array}$ & & 3 & 88.275 & & & 82.730 & \\
\hline $\begin{array}{l}\text { SS mean lipid } \\
\text { droplet area }\left(\mu \mathrm{m}^{2}\right)\end{array}$ & 0.244 & 0.106 & $\begin{array}{ll}0.188 \quad \text { to } \\
0.301\end{array}$ & 0.368 & 0.137 & $\begin{array}{l}0.292 \\
0.444\end{array}$ & to \\
\hline $\begin{array}{l}\text { SS proportion } \\
\text { lipid droplet area } \\
(\%)\end{array}$ & 4.075 & 2.086 & $\begin{array}{ll}2.964 & \text { to } \\
5.186 & \end{array}$ & 4.758 & 2.198 & $\begin{array}{l}3.541 \\
5.975\end{array}$ & to \\
\hline $\begin{array}{l}\text { SS \# lipid } \\
\text { droplets/total area } \\
\left(\# / \mu \mathrm{m}^{2}\right)\end{array}$ & 0.168 & 0.071 & $\begin{array}{ll}0.130 \quad \text { to } \\
0.205\end{array}$ & 0.145 & 0.083 & $\begin{array}{l}0.099 \\
0.190\end{array}$ & to \\
\hline $\begin{array}{l}\text { IMF lipid droplets } \\
\text { touching } \\
\text { mitochondria }(\%)\end{array}$ & 78.396 & 8.054 & $\begin{array}{l}74.104 \text { to } \\
82.687\end{array}$ & 69.050 & 12.961 & $\begin{array}{l}61.872 \\
76.228\end{array}$ & to \\
\hline $\begin{array}{l}\text { IMF mean lipid } \\
\text { droplet area }\left(\mu \mathrm{m}^{2}\right)\end{array}$ & 0.221 & 0.041 & $\begin{array}{l}0.199 \text { to } \\
0.243\end{array}$ & 0.223 & 0.069 & $\begin{array}{l}0.184 \\
0.261\end{array}$ & to \\
\hline $\begin{array}{l}\text { IMF proportion } \\
\text { lipid droplet area } \\
(\%)\end{array}$ & 0.502 & 0.310 & $\begin{array}{l}0.337 \text { to } \\
0.667\end{array}$ & 0.555 & 0.296 & $\begin{array}{l}0.392 \\
0.719\end{array}$ & to \\
\hline \multirow[t]{2}{*}{$\begin{array}{l}\text { IMF \# lipid } \\
\text { droplet/total area } \\
\left(\# / \mu \mathrm{m}^{2}\right)\end{array}$} & 0.021 & 0.013 & $\begin{array}{ll}0.015 \quad \text { to } \\
0.028\end{array}$ & 0.024 & 0.012 & $\begin{array}{l}0.017 \\
0.031\end{array}$ & to \\
\hline & Median & IQR & Min-max & Median & IQR & Min-max & \\
\hline Irregular fibers & Patient $\mathrm{g}$ & oup $(n=$ & 10) & Control & $\mathrm{p}(\mathrm{n}=12)$ & & \\
\hline Fibers & 13.905 & 4.580 & 5.190 & 7.691 & 6.510 & 4.750 & - \\
\hline
\end{tabular}




\begin{tabular}{|c|c|c|c|c|c|c|c|}
\hline $\begin{array}{l}\text { irregular COX } \\
\text { staining (\%) }\end{array}$ & & & 26.250 & & & & 22.030 \\
\hline Irregular fibers & \multicolumn{3}{|c|}{ Patient group $(n=11)$} & & \multicolumn{3}{|c|}{ Control group $(n=11)$} \\
\hline $\begin{array}{l}\text { Fibers with } \\
\text { irregular NADH } \\
\text { staining (\%) }\end{array}$ & 6.601 & $\begin{array}{l}14.21 \\
0\end{array}$ & $\begin{array}{l}0.740 \\
23.200\end{array}$ & & 6.794 & 5.140 & $\begin{array}{l}3.270 \\
11.920\end{array}$ \\
\hline Irregular fibers & \multicolumn{4}{|c|}{ Patient group $(\mathrm{n}=11)$} & \multicolumn{3}{|c|}{ Control group $(n=11)$} \\
\hline $\begin{array}{ll}\text { Fibers } & \text { with } \\
\text { irregular } & \text { SDH } \\
\text { staining (\%) } & \end{array}$ & 6.404 & 7.940 & $\begin{array}{l}0.000 \\
11.530\end{array}$ & - & 2.083 & 5.550 & $0.260-12.960$ \\
\hline
\end{tabular}

$\mathrm{n}$ : number of subjects, SD: standard deviation, 95\% CI: 95\% confidence interval, IQR: interquartile range, SS: subsarcolemmal, IMF: intermyofibrillar, COX: cytochrome c oxidase, NADH: nicotinamide adenine dinucleotide, $\mathrm{SDH}$ : succinate dehydrogenase 
TABLE 3 Results from multiple linear regression analysis: mitochondrial morphology, lipid droplet and irregular fibers

\begin{tabular}{|c|c|c|c|c|c|}
\hline Mitochondrial morphology & $\mathrm{F}$ & Slope (95 \% CI) & $\begin{array}{l}\text { Adjuste } \\
\mathrm{d} \mathrm{R}^{2}\end{array}$ & $\begin{array}{l}\text { P-value } \\
\text { of model }\end{array}$ & $\begin{array}{l}\text { P-value } \\
\text { for } \\
\text { group* }\end{array}$ \\
\hline $\begin{array}{l}\text { SS mean mitochondrial area } \\
\left(\mu \mathrm{m}^{2}\right)\end{array}$ & 1.729 & $\begin{array}{lll}0.021 \quad(0.030 \quad \text { to } \\
0.039) & \end{array}$ & 0.089 & 0.174 & 0.023 \\
\hline $\begin{array}{l}\text { SS proportion mitochondrial } \\
\text { area }(\%)\end{array}$ & 2.595 & $\begin{array}{ll}3.894 & (-0.842 \text { to } \\
8.630) & \end{array}$ & 0.175 & 0.060 & 0.103 \\
\hline $\begin{array}{l}\text { SS \# mitochondria/total area } \\
\left(\# / \mu \mathrm{m}^{2}\right)\end{array}$ & 1.774 & $\begin{array}{l}0.344 \quad(-0.350 \text { to } \\
1.038)\end{array}$ & 0.094 & 0.164 & 0.318 \\
\hline $\begin{array}{l}\text { IMF mean mitochondrial } \\
\text { area }\left(\mu \mathrm{m}^{2}\right)\end{array}$ & 1.791 & $\begin{array}{ll}0.009 & (0.000 \text { to } \\
0.019) & \end{array}$ & 0.095 & 0.161 & 0.051 \\
\hline $\begin{array}{l}\text { IMF proportion } \\
\text { mitochondrial area }(\%)\end{array}$ & 2.352 & $\begin{array}{lll}0.700 \quad(0.078 \text { to } \\
1.321) & & \end{array}$ & 0.153 & 0.080 & 0.029 \\
\hline $\begin{array}{l}\text { IMF \# mitochondria/ total } \\
\text { area }\left(\# / \mu \mathrm{m}^{2}\right)\end{array}$ & 0.445 & $\begin{array}{ll}0.025 \quad(-0.054 \text { to } \\
0.105)\end{array}$ & -0.080 & 0.775 & 0.521 \\
\hline Lipid droplets & $\mathrm{F}$ & Slope & $\begin{array}{l}\text { Adjuste } \\
\mathrm{d} \mathrm{R}^{2}\end{array}$ & $\begin{array}{l}\text { P-value } \\
\text { of model }\end{array}$ & $\begin{array}{l}\text { P-value } \\
\text { for } \\
\text { group* }\end{array}$ \\
\hline $\begin{array}{l}\text { SS proportion lipid droplets } \\
\text { touching mitochondria }(\%)\end{array}$ & 0.867 & $\begin{array}{ll}8.754 \quad(-7.009 \text { to } \\
24.517)\end{array}$ & -0.018 & 0.497 & 0.264 \\
\hline SS mean lipid droplet area & 2.020 & $-0.135(-0.240$ to - & 0.120 & 0.121 & 0.015 \\
\hline
\end{tabular}




\begin{tabular}{|c|c|c|c|c|c|}
\hline$\left(\mu \mathrm{m}^{2}\right)$ & & $0.029)$ & & & \\
\hline $\begin{array}{l}\text { SS proportion lipid droplet } \\
\text { area }(\%)\end{array}$ & 1.305 & $\begin{array}{ll}-0.419 \quad(-2.157 \text { to } \\
1.319) & \end{array}$ & 0.039 & 0.294 & 0.624 \\
\hline $\begin{array}{l}\text { SS \# lipid droplet /total area } \\
\left(\# / \mu \mathrm{m}^{2}\right)\end{array}$ & 1.852 & $\begin{array}{lll}0.034 & (-0.026 \text { to } \\
0.094) & \end{array}$ & 0.102 & 0.149 & 0.260 \\
\hline $\begin{array}{l}\text { IMF lipid droplet touching } \\
\text { mitochondria }(\%)\end{array}$ & 2.280 & $\begin{array}{lll}9.620 \quad(0.752 \text { to } \\
18.493) & & \end{array}$ & 0.146 & 0.088 & 0.035 \\
\hline $\begin{array}{l}\text { IMF mean lipid droplet area } \\
\left(\mu \mathrm{m}^{2}\right)\end{array}$ & 1.077 & $\begin{array}{lll}-0.008 \quad(-0.054 \text { to } \\
0.038) & & \end{array}$ & 0.010 & 0.388 & 0.723 \\
\hline $\begin{array}{l}\text { IMF proportion lipid droplet } \\
\text { area }(\%)\end{array}$ & 1.669 & $\begin{array}{ll}-0.010 \quad(-0.248 \text { to } \\
0.228)\end{array}$ & 0.082 & 0.187 & 0.933 \\
\hline $\begin{array}{l}\text { IMF \# lipid droplet /total } \\
\text { area }\left(\# / \mu \mathrm{m}^{2}\right)\end{array}$ & 2.240 & $\begin{array}{l}0.000 \quad(-0.009 \text { to } \\
0.009)\end{array}$ & 0.142 & 0.092 & 0.984 \\
\hline Irregular fibers & $\bar{F}$ & Slope & $\begin{array}{l}\text { Adjuste } \\
\mathrm{d} \mathrm{R}^{2}\end{array}$ & $\begin{array}{l}\text { P-value } \\
\text { of model }\end{array}$ & $\begin{array}{l}\text { P-value } \\
\text { for } \\
\text { group* }\end{array}$ \\
\hline $\begin{array}{l}\text { Fibers with irregular COX } \\
\text { staining }(\%)\end{array}$ & 1.696 & $\begin{array}{lll}5.861 \quad(0.652 \text { to } \\
11.070) & \end{array}$ & 0.117 & 0.197 & 0.030 \\
\hline $\begin{array}{l}\text { Fibers with irregular NADH } \\
\text { staining }(\%)\end{array}$ & 1.796 & $\begin{array}{lll}3.998 & (-1.305 \text { to } \\
9.300) & & \end{array}$ & 0.132 & 0.176 & 0.130 \\
\hline $\begin{array}{l}\text { Fibers with irregular SDH } \\
\text { staining }(\%)\end{array}$ & 0.629 & $\begin{array}{lll}1.909 & (-2.057 \text { to } \\
5.874) & & \end{array}$ & -0.076 & 0.649 & 0.324 \\
\hline
\end{tabular}


95\% CI: 95\% confidence interval, SD: standard deviation, 95\% CI: 95\% confidence interval, SS: subsarcolemmal, IMF: intermyofibrillar, COX: cytochrome c oxidase, NADH: nicotinamide adenine dinucleotide, SDH: succinate dehydrogenase Statistical analyses were performed using multiple linear regression analysis. Age, hours of computer work/week and upper limb sports were included as covariates.

* Statistical significance was accepted when $\mathrm{P}<0.05$ 